The observation that many recipients clearly incompatible for the defined HL-A antigens also had a prolonged benign course-that is, no rejections-is consistent with the findings of Terasaki et al. 1967) and of Dausset et al. (1968) and additionally emphasizes the lack of complete correlation between HL-A matching and clinical course. The reasons for this discrepancy are likely to be complex, including the inherent immunological competence of the recipient and the effect of uraemia, his response to immunosuppressive drugs, the immunogenicity of the antigens in question, and whether or not the antigens cross-reacting with the incompatible donor antigens are present in the recipient (Kissmeyer-Nielsen et al, 1968). The fact that HL-A identical grafts showed a superior function even within the first two weeks of transplantation is not without interest, since authorities (Terasaki et al., 1966; Rapaport et al., 1967) have tended to emphasize only the late correlates of typing. Though a correlation exists between the immediate function of the graft and the duration of warm ischaemia (Carroll et al., 1969), this does not appear to hold as well with warm ischaemia times of less than an hour (Belzer et al., 1970). The range of total ischaemia time in these patients was 22 to 39 minutes. Because, however, of the many variables (some unknown) involved in the early function of the graft it is not possible to attribute this superior result to histocompatibility matching per se.

Though admittedly the period of follow-up for the HL-A identical patients was much shorter than that for the HL-A compatible and incompatible patients, the completely benign course shown by these patients over comparable periods of time is impressive. A longer follow-up should be especially interesting, since skin grafts exchanged between unmodified HL-A identical siblings are eventually rejected after a mean survival of 23 days in contrast to 11 days in the control group (Amos and Bach, 1968). Evidently, in the case of the skin minor non-HL-A antigen systems can exert their influence after a prolonged interval. It remains to be seen whether this will be the case also in HL-A identical kidney transplants under immunosuppression, especially in the light of the differences in immunological behaviour between skin and kidney transplants in experimental animals (Sakai et al., 1969).

We are indebted to Drs. J. P. Merrill, J. E. Murray, R. E. Wilson, and A. G. Birtch for their suggestions and encouragement. The transplants reported in this paper were performed by Drs. J. E. Murray, J. H. Harrison, R. E. Wilson, and A. G. Birtch. The statistical analyses were done by Dr. John Atkinson, of the Harvard Computing Facility.

This work was supported by grants AI-06091 and AI-04606 from the U.S. Public Health Service, and by grants from the United States Army Research and Development Command, from the Atomic Energy Commission, and from the John A. Hartford Foundation.

\section{REFERENCES}

Amos, D. B., and Bach, F. H. (1968). Fournal of Experimental Medicine

Amos, D. B., and Zmijewski, C. M. (1967). Proceedings of the Third International Congress of Nephrology, Washington, D.C., 1966, ed. G. E. Schreiner, p. 341. Basel, Karger.

Belzer, F. O., Reid, T. W., Pryor, J. P., Kountz, S. L., and Dunphy, J. E. (1970). Surgery, Gynecology and Obstetrics, 130, 467.

Carpenter, C. B., and Merrill, J. P. (1969). Archives of Internal Medicine, 123, 501 .

Carroll, R. N. P., Chisholm, G. D., and Shackman, R. (1969). Lancet, 2, 551

Dausset, J., Rapaport, F. T., and Legrand, C. (1968). In Advance in Transplantation, ed. J. Dausset, J. Hamburger, and G. Mathé, p. 749. Baltimore, Williams and Wilkins.

Hume, D. M., et al. (1966). Annals of Surgery, 164, 352.

Kissmeyer-Nielsen, F., Svejgaard, A., and Hauge, M. (1968). Nature, 219, 1116.

Lee, H. M., Hume, D. M., Vredevoe, D. L., Mickey, M. R., and Terasaki, P. I. (1967). Transplantation, 5, 1040.

Murray, J. E., et al. (1968). Annals of Surgery, 168, 416.

Patel, R., Mickey, M. R., and Terasaki, P. I. (1969). British Medical fournal,

2, 424.
Rapaport, F. T., and Dausset, J. (1969). Progress in Cardiovascular Diseases, $12,119$.

Rapaport, F. T., et al. (1967). Annals of Surgery, 166, 596.

Sakai, A., Simonsen, M., and Jensen, E. (1969). Transplantation, 7, 444.

Starzl, T. E. (1964). Experience in Renal Transplantation, p. 130. Philadelphia, Saunders.

Terasaki, P. I., et al. (1966). Annals of the New York Academy of Sciences, 129,500 .

Terasaki, P. I., and McClelland, J. D. (1964). Nature, 204, 998.

Terasaki, P. I., Vredevoe, D. L., and Mickey, M. R. (1967). Transplantation,

5, 1057 .
Tilney, N. L., Atkinson, J. C., and Murray, J. E. (1970). Annals of Internal Medicine, 72, 59.
- Consultant Physician in General Medicine, Eastern General Hospital, Edinburgh EH6 7LN

† Registrar in General Medicine, Royal Infirmary, Edinburgh 3.

F Medical Superintendent, Astley Ainslie Hospital, Edinburgh EH9 2HL.

Consultant Physician in Diabetic and Dietetic Department, Royal Infirmary, Edinburgh 3.

\section{Introduction}

Starvation is an effective method of losing weight but is justified only if it produces a lasting effect. We report the results of this treatment in 25 patients with refractory obesity who agreed to be starved in hospital until they had reduced to within $25 \%$ in excess of their ideal weight.

\section{Patients and Methods}

Fourteen women and 11 men were selected (see Table). All had gross refractory obesity (Duncan et al., 1960), had previously failed to respond to other forms of treatment, and were apparently anxious to starve in hospital until they had attained an acceptable weight. Most were admitted to a rehabilitation centre, where they were encouraged to use fully the various facilities available. They were allowed to drink as much water, black coffee, tea, and acaloric fruit juice as they wished; however, a low-calorie carbohydrate-restricted meal was given if specifically requested. Many took one such meal a week, but the emphasis was on trust rather than super- 
TABLE I.-Details of Patients

\begin{tabular}{|c|c|c|c|c|c|c|c|c|c|c|c|c|c|c|c|}
\hline \multirow{2}{*}{$\begin{array}{l}\text { Case } \\
\text { No. }\end{array}$} & \multirow[t]{2}{*}{ Age } & \multirow[t]{2}{*}{ Sex } & \multirow{2}{*}{$\begin{array}{c}\text { Ideal } \\
\text { Weight } \\
(\mathbf{k g} .)\end{array}$} & \multicolumn{2}{|c|}{$\begin{array}{c}\text { Excess Weight } \\
\text { Before Fast } \\
\text { (kg.) }\end{array}$} & \multicolumn{2}{|c|}{$\begin{array}{l}\text { Excess Weight } \\
\text { at Fast }\end{array}$} & \multirow{2}{*}{$\begin{array}{c}\text { Duration } \\
\text { of } \\
\text { Fast } \\
\text { (Daya) }\end{array}$} & \multicolumn{2}{|c|}{$\begin{array}{l}\text { Ercesa Weight } \\
\text { on Discharge }\end{array}$} & \multicolumn{2}{|c|}{$\begin{array}{l}\text { Excess Weight } \\
\text { after Discharge } \\
\text { (kg.) }\end{array}$} & \multicolumn{2}{|c|}{$\begin{array}{c}\text { Final Excess } \\
\text { Weight }\end{array}$} & \multirow{2}{*}{$\begin{array}{l}\text { Length } \\
\text { of } \\
\text { Follow-u } \\
\text { (Months) }\end{array}$} \\
\hline & & & & $\underset{\text { Months }}{\text { Six }}$ & $\begin{array}{l}\text { Three } \\
\text { Months }\end{array}$ & kg. & $\begin{array}{l}\% \text { Ideal } \\
\text { Weight }\end{array}$ & & kg. & $\begin{array}{l}\% \text { Ideal } \\
\text { Weight }\end{array}$ & $\begin{array}{l}\text { Three } \\
\text { Months }\end{array}$ & $\begin{array}{c}\text { Six } \\
\text { Months }\end{array}$ & kg. & $\begin{array}{l}\% \text { Ideal } \\
\text { Weight }\end{array}$ & \\
\hline $\begin{array}{r}1 \\
2 \\
3 \\
4 \\
5 \\
6 \\
7 \\
8 \\
9 \\
10 \\
11 \\
12 \\
13 \\
14 \\
15 \\
16 \\
17 \\
18 \\
19 \\
20 \\
21 \\
22 \\
23 \\
24 \\
25\end{array}$ & $\begin{array}{l}24 \\
21 \\
21 \\
29 \\
22 \\
45 \\
47 \\
21 \\
21 \\
19 \\
18 \\
52 \\
33 \\
21 \\
22 \\
20 \\
53 \\
23 \\
35 \\
26 \\
37 \\
19 \\
16 \\
29 \\
40\end{array}$ & $\begin{array}{l}\text { F. } \\
\text { M. } \\
F . \\
F . \\
F . \\
F . \\
F . \\
F . \\
M . \\
M . \\
F . \\
M . \\
M . \\
M . \\
F . \\
F . \\
F . \\
F . \\
F . \\
M . \\
M . \\
M . \\
F . \\
M . \\
M .\end{array}$ & $\begin{array}{l}66 \cdot 2 \\
72 \cdot 6 \\
57 \cdot 6 \\
60 \cdot 8 \\
64 \cdot 4 \\
69 \cdot 9 \\
68 \cdot 0 \\
62 \cdot 6 \\
75 \cdot 3 \\
72 \cdot 1 \\
63 \cdot 5 \\
69 \cdot 9 \\
74 \cdot 8 \\
66 \cdot 7 \\
68 \cdot 0 \\
58 \cdot 0 \\
44 \cdot 5 \\
59 \cdot 0 \\
54 \cdot 4 \\
64 \cdot 4 \\
64 \cdot 4 \\
61 \cdot 7 \\
61 \cdot 7 \\
68 \cdot 0 \\
69 \cdot 9\end{array}$ & $\begin{array}{l}66 \cdot 2 \\
43 \cdot 5 \\
59 \cdot 9 \\
40 \cdot 4 \\
49 \cdot 9 \\
43 \cdot 5 \\
97 \cdot 0 \\
39 \cdot 0 \\
42 \cdot 6 \\
56 \cdot 7 \\
49 \cdot 0 \\
49 \cdot 4 \\
70 \cdot 8 \\
46 \cdot 7 \\
49 \cdot 4 \\
37 \cdot 2 \\
25 \cdot 4 \\
38 \cdot 6 \\
43 \cdot 0 \\
38 \cdot 1 \\
66 \cdot 2 \\
31 \cdot 8 \\
47.6 \\
31 \cdot 8 \\
44 \cdot 0\end{array}$ & $\begin{array}{l}67 \cdot 1 \\
39 \cdot 5 \\
60 \cdot 3 \\
39 \cdot 0 \\
48 \cdot 1 \\
44 \cdot 9 \\
95 \cdot 7 \\
37 \cdot 6 \\
47 \cdot 6 \\
62 \cdot 1 \\
48 \cdot 1 \\
50 \cdot 8 \\
74 \cdot 8 \\
42 \cdot 2 \\
52 \cdot 2 \\
36 \cdot 7 \\
26 \cdot 3 \\
41 \cdot 7 \\
39 \cdot 9 \\
35 \cdot 8 \\
63 \cdot 0 \\
28 \cdot 1 \\
46 \cdot 3 \\
29.9 \\
45 \cdot 4\end{array}$ & $\begin{array}{l}67 \cdot 1 \\
41 \cdot 3 \\
66 \cdot 7 \\
38 \cdot 1 \\
47 \cdot 6 \\
45 \cdot 4 \\
94 \cdot 3 \\
36 \cdot 7 \\
48 \cdot 0 \\
68 \cdot 5 \\
46 \cdot 3 \\
50 \cdot 8 \\
78 \cdot 5 \\
40 \cdot 4 \\
52 \cdot 2 \\
35 \cdot 8 \\
26 \cdot 8 \\
43 \cdot 5 \\
39 \cdot 9 \\
36 \cdot 3 \\
78 \cdot 5 \\
27 \cdot 2 \\
47 \cdot 2 \\
29.9 \\
44 \cdot 9\end{array}$ & $\begin{array}{r}101 \\
57 \\
116 \\
63 \\
74 \\
65 \\
139 \\
59 \\
64 \\
96 \\
73 \\
73 \\
105 \\
61 \\
77 \\
64 \\
60 \\
72 \\
74 \\
56 \\
122 \\
44 \\
76 \\
44 \\
64\end{array}$ & $\begin{array}{r}4 \\
30 \\
62 \\
119 \\
85 \\
83 \\
110 \\
25 \\
49 \\
122 \\
82 \\
105 \\
196 \\
54 \\
112 \\
100 \\
100 \\
68 \\
105 \\
56 \\
154 \\
40 \\
84 \\
38 \\
82\end{array}$ & $\begin{array}{r}64 \cdot 0 \\
31.3 \\
39.5 \\
15.0 \\
19.1 \\
16.3 \\
53.5 \\
27.2 \\
29.5 \\
25.4 \\
20.4 \\
19.5 \\
19.5 \\
15.0 \\
10.4 \\
11.8 \\
5.9 \\
14.5 \\
13.2 \\
15.0 \\
15.0 \\
11.8 \\
11.3 \\
9.5 \\
6.4\end{array}$ & $\begin{array}{r}96 \\
45 \\
69 \\
25 \\
30 \\
23 \\
79 \\
43 \\
39 \\
36 \\
32 \\
28 \\
26 \\
22 \\
15 \\
20 \\
13 \\
25 \\
24 \\
23 \\
23 \\
19 \\
18 \\
14 \\
9\end{array}$ & $\begin{array}{r}20.4 \\
54.0 \\
27.2 \\
26.3 \\
15.0 \\
24.9 \\
31.8 \\
25.9 \\
20.0 \\
15.4 \\
15.4 \\
7.7 \\
12.2 \\
15.0 \\
15.4 \\
14.1 \\
10.9 \\
14.5 \\
11.3 \\
6.4\end{array}$ & $\begin{array}{r}59.9 \\
27.7 \\
30.4 \\
17.2 \\
25.4 \\
27.2 \\
39.5 \\
24.0 \\
25.4 \\
17.2 \\
10.4 \\
12.7 \\
12.7 \\
13.2 \\
11.8 \\
10.9 \\
15.4 \\
13.6 \\
6.4\end{array}$ & $\begin{array}{l}69.9 \\
31.8 \\
36 \cdot 7 \\
29.5 \\
25.4 \\
27 \cdot 2 \\
39.5 \\
33.1 \\
30.4 \\
18 \cdot 1 \\
13 \cdot 2 \\
10.0 \\
13.2 \\
14.5 \\
10.9 \\
10.9 \\
15.9 \\
14.5 \\
15.4\end{array}$ & $\begin{array}{r}103 \\
51 \\
49 \\
41 \\
40 \\
39 \\
53 \\
50 \\
45 \\
31 \\
30 \\
17 \\
24 \\
23 \\
17 \\
18 \\
26 \\
21 \\
23\end{array}$ & $\begin{array}{r}15 \\
22 \\
13 \\
17 \\
16 \\
6 \\
6 \\
16 \\
19 \\
20 \\
12 \\
17 \\
24 \\
22 \\
16 \\
8 \\
18 \\
20 \\
18\end{array}$ \\
\hline
\end{tabular}

vision and a few patients openly ate more. Vitamins, potassium supplements, iron, and allopurinol were given routinely, with sedation as required. Patients were weighed twice weekly, and daily blood-pressure recordings and urine tests for ketones were made. Plasma electrolytes, venous bicarbonate, and uric acid were estimated twice weekly and electrocardiograms were taken at regular intervals. Several days before discharge a low-calorie diet was given. Before going home the patients were seen in the out-patient department and weighed in their usual clothing. Thereafter they reported at intervals of four weeks or less, were weighed on the same pair of scales in much the same clothing, were interviewed by the same group of doctors, were offered further dietary advice, and were given every form of encouragement to lose weight. Many received one or more short courses of an anorexiant drug and two were readmitted for a further period of starvation (Cases 14 and 24).

\section{Results}

Most patients tolerated the regimen surprisingly well, but two developed symptoms attributable to hypotension and hypokalaemia, and in one patient (Case 19) these were of such severity as to necessitate temporarily discontinuing starvation. One patient, in whom treatment with allopurinol had been inadvertently omitted, experienced an attack of clinical gout, two patients temporarily developed alopecia, and two required cosmetic surgery for unsightly skin folds.

Two patients (Cases 1 and 2) took their own discharge and clearly were psychologically unsuited to this form of treatment. Two (Cases 3 and 4) defaulted immediately after discharge and two (Cases 5 and 6) a few months later. Seven patients (Cases 7-13) were discharged from hospital for psychological and/or social reasons or because they had stopped losing weight when still more than $25 \%$ in excess of their ideal weight; all have regained weight (Fig. 1). The remaining 12 were discharged weighing not more than $25 \%$ in excess of their ideal weight, at a stage when it was felt that the purpose of admission had been achieved. Four (Cases 14-17) have regained a significant amount of weight but eight (Cases 1825) remain near their discharge weight (Fig. 2).

\section{Discussion}

Various complications, including death, have been reported during therapeutic starvation (Cubberley et al. 1965; Spencer, 1968; Garnett et al., 1969; Runcie and Thomson, 1970). Run- cie and Thomson also reported breakdown in renal electrolytc homoeostasis, and this could account for the side effects that developed in one or two of our patients. It has been suggested that it may also be responsible for some of the deaths and that, provided appropriate precautions are taken, the risks of starvation are justified in view of the increased

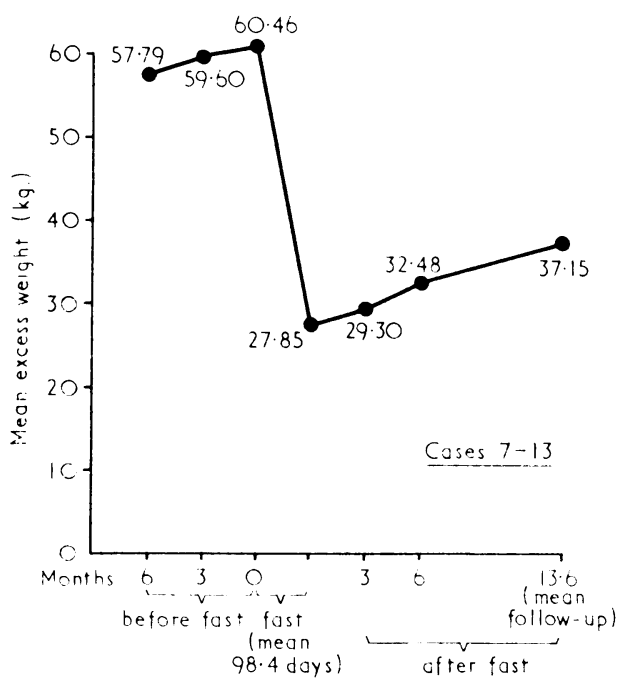

Fig. 1.-Data of patients who failed to reduce to within $25 \%$ excess of mean weight.

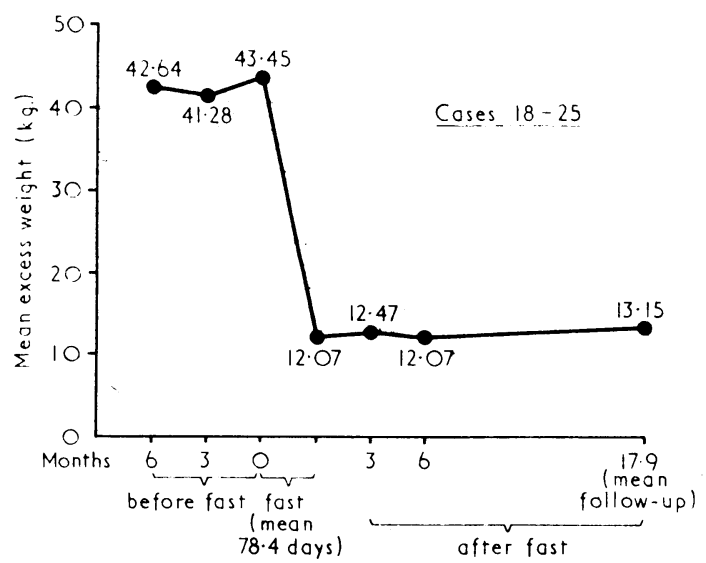

FIG. 2.-Data of the eight patients who remained within $25 \%$ of mean weight. 
morbidity and mortality associated with gross obesity. In addition, we believe that starvation is of value only if it results in permanent weight reduction. Previous experience has shown that almost all obese patients starved for a relatively short time and allowed home while still clinically obese soon regain weight (MacCuish et al., 1968).

This further study was undertaken to determine if more satisfactory results could be obtained by starving obese patients until they have reduced to $25 \%$ in excess of their ideal weight. Thirteen failed to lose weight to this extent. These include many of the most grossly obese in whom reduction to less than $25 \%$ excess body weight would have required a long stay in hospital. Those who have not defaulted have all regained weight, and though they remain much lighter than before admission, the velocity of their gain is comparable to that observed in the previous study. The long-term prognosis is considered to be poor. Clearly some of them were psychologically unsuitable for this form of treatment, and their admission might have been avoided by the use of formal psychological evaluation. In contrast, 8 of the 12 who did achieve the desired loss of weight have not regained appreciably though they have required constant supervision. All admit to a radical change in previous eating habits and feel that the main value of starvation has been an improvement in physical and psychological well-being.

These results would appear to confirm our initial impression that starvation of the grossly obese is more likely to be successful in the long term if continued until a weight approaching the ideal is achieved. Whether this can be attributed to increased psychological incentive or to some more fundamental change in eating pattern or body metabolisr 1 subsequent to effective weight loss remains to be determin d.

REFERENCES

Cubberley, P. T., Polster, S. A., and Schulman, C. L. (1965). New England fournal of Medicine, 272,628

Duncan, L. J. P., Rose, K., and Meiklejohn, A. P. (1960). Lancet, 1, 1262. Garnett, E. S., Barnard, D. L., Ford, J., Goodbody, R. A., and Woodehouse,

M. A. (1969). Lancet, 1, 914.
MacCuish, A. C., Munro, J. F., and Duncan, L. J. P. (1968). British Medical fournal, 1, 91 .

Runcie, J., and Thomson, T. J. (1970). British Medical fournal, 3, 432.

Spencer, I. O. B. (1968). Lancet, 1, 1288.

\title{
Production of Epigastric Pain in Duodenal Ulcer by Lower Oesophageal Acid Perfusion
}

\author{
RICHARD J. EARLAM,* M.CHIR., F.R.C.s.
}

Cummary: Thirty-six patients with duodenal ulceration $\checkmark$ were divided into group 1 (30), who had epigastric pain, and group 2 (6), who had pain in the upper abdomen but not in the epigastrium, and were studied by perfusing the lower oesophagus with dilute acid in an attempt to reproduce epigastric pain. In group 1, 25 suffered epigastric pain, indistinguishable from that which they normally had, after perfusion of $30 \mathrm{ml}$. of $0.1 \mathrm{~N}$ HCl in under four minutes (mean values), but none of group 2 had pain.

\section{Introduction}

Pain associated with duodenal ulcer may be experienced in the epigastrium, under the right costal margin, around the umbilicus, or between the umbilicus and the xiphisternum in the midline, but there has never been any conclusive evidence as to its origin. Referred pain from the duodenum may be caused by the local action of acid on an ulcer, and inflation of balloons in the duodenum may also cause pain in any of these areas (Bloomfield and Polland, 1931). The stomach is usually insensitive to high levels of acid, though some attempts have succeeded in producing pain (Palmer, 1926; Bonney and Pickering, 1946; Smith, 1955). Because these experiments on the stomach and duodenum have not consistently reproduced epigastric pain it was considered that acid reflux on to a sensitive lower oesophageal mucosa might be a cause. Distension of the lower oesophagus causes lower sternal pain hut may also cause epigastric pain (Polland and Bloomfield, 1931), and perfusion of this region with acid in hiatal hernia has been used as a clinical test for the retrosternal pain of oesophagitis with the occasional production of epigastric pain as well (Bernstein and Baker, 1958).

In this study the oesophageal acid perfusion test was modified for the investigation of epigastric pain. The localization of epigastric pain was recorded on a small diagram after

- Senior Lecturer in Surgery, the London Hospital, London E.1. the patient had pointed to the site in question with one finger and after this had been confirmed by the doctor also pressing the area in question. The definition of epigastric pain was "that pain between the rib margin just below the xiphisternum." Since bony landmarks were used as a reference point there was not so much inaccuracy as would have occurred if somewhere in the centre of the abdomen had been pointed out.

\section{Patients and Methods}

Thirty-six patients with a duodenal ulcer were divided into two groups on the basis of whether they had epigastric pain or not. Thirty patients in group 1 had epigastric pain in the angle between the rib margins just below the xiphisternum. Six patients in group 2 had other upper abdominal painthree complained of upper abdominal fullness, two had periumbilical pain, and one had a lower sternal ache. All had had this pain in the previous four weeks, but in the present study no distinction was made because of its severity or last occurrence, so that patients who had been woken by pain during the night before the test were not differentiated from those who had only occasional pain after meals.

Pressure measurements of the gastro-oesophageal iunction were made with techniques previously described (Fyke et al. 1956). No uniform preparation of the patients was made; some had just eaten and others had fasted overnight. The recording units (Fig. 1) were passed through the mouth into the patient's stomach. Pressure measurements were made with three water-filled polyethylene tubes (external diameter 0.065 in. $(1.65 \mathrm{~mm}$.); internal diameter $0.044 \mathrm{in}$. $(1.12 \mathrm{~mm}$.)) The distal tube was covered with a $0.5-\mathrm{cm}$. balloon, and the two remaining tubes had lateral openings 5 and $10 \mathrm{~cm}$. from the balloon. SE 4-8 Mk 2 transducers converted pressure to electrical activity, which was recorded by an SE 20056 -channel ultraviolet recorder on 6 -in. $(15-\mathrm{cm}$.) paper. A pH stomach electrode (Pye 240 E07) was tied $0.5 \mathrm{~cm}$. proximal 